\title{
Code red: Towards authentic transformational leadership of emergency management
}

\author{
Denis HJ Caro * \\ University of Ottawa/Université d'Ottawa, Telfer School of Management, Ottawa, Ontario, Canada
}

Received: May 3, 2015

DOI: $10.5430 /$ jha.v4n5p67
Accepted: July 1, 2015

URL: http://dx.doi.org/10.5430/jha.v4n5p67

\begin{abstract}
In this $21^{\text {st }}$ century of unprecedented global, national and regional threats and innovative technologies, this study underscores the unique authentic transformational leadership challenges posed in emergency management systems. These open complex systems adapt to a range of critical emergency events, including mass emergencies, disasters and catastrophes. This qualitative research study based on grounded theory examines the phenomenology of emergency management systems by deploying triangulation to isolate the particular theoretical underpinnings of authentic transformational leadership models relevant to this domain. Using a key informant approach and a semi-structured confidential questionnaire, the perspectives of 103 emergency, health care and technological leaders of diverse professional backgrounds on the challenges of emergency management systems are presented. The response rate was 83.5 percent from 81 organizations across Canada. This study underscores the need for authentic transformational leadership and identifies seven critical and specific leadership imperatives for this domain. The implications for hospital and health care administrators are also presented. This qualitative study of diverse emergency system leaders is original in that it has not hitherto been done across Canada nor internationally. This study underscores the relevance of leadership theory and principles in the extant literature, but extends this to highlight those that are critical and unique to leaders of emergency management systems. In so doing, calls on the need for authentic transformation leadership of an order and caliber yet to be fully potentiated to manage future emergency events in Canada.
\end{abstract}

Key Words: Emergency management, Systems, Leadership, Qualitative research, Key informants, Grounded theory

\section{INTRODUCTION}

Emergency management systems require authentic transformational leadership of an order not yet fully potentiated in Canada. Such systems encompass management and care processes inherent in three critical events: mass emergencies, disasters and catastrophes. Emergencies are small-scale, common and largely predictable events that are managed with regional resources. Disasters are those that overwhelm regional resources and require multi-regional emergency responses and collaboration. Typically, mortality and morbid- ity exceed 10 and 100 persons respectively. Catastrophes are extreme disasters that paralyze, or destroy, critical community infrastructures and require multi-regional, national and international responses. For all of these events, the extant literature underscores the critical importance of emergency leadership. ${ }^{[1-14]}$ The safety and well-being of individuals and the integrity of communities remain the core mission of emergency management systems. No qualitative research studies on emergency management systems leadership have been carried out in Canada nor internationally in this area.

*Correspondence: Dr. Denis H.J. Caro; Email: drcaro@ uottawa.ca; Address: Telfer School of Management, University of Ottawa/Université d' Ottawa, Ottawa, Ontario, Canada. 
Using grounded theory and a triangulation approach, the theoretical framework of this study was based on pertinent leadership models in open adaptive complex systems constructs. Based on this study of key informants, the importance of and need for authentic transformational leadership in emergency management systems emerged as one of the central themes. Moreover, seven critical leadership imperatives specific to such systems are posited.

\subsection{Theoretical framework: a triangulation approach}

The extant literature in health care systems underscores the importance of transformational leadership in the quest for greater efficiency, effectiveness and performance excellence. ${ }^{[15-24]}$ Moreover, the literature also stresses the complementary importance of authentic leadership in inspiring and fostering mutual respect, open inter-professional communication, collaborative decision-making all of which motivate a commitment to high quality systems of care. ${ }^{[25-29]}$ Authentic transformational leadership is the backbone of high-performing and highly effective health care systems, as evidenced through quality of care, patient satisfaction, workforce satisfaction, organizational effectiveness, performance and social responsibility. ${ }^{[30,31]}$ Authentic transformational leadership engages and motivates professionals to collaborate in integrating their work horizontally and vertically in emergency management systems. This leadership is also necessary in bringing about transformational changes within integrated health care delivery systems accountable for the overall positive outcomes that include lower mortality and morbidity rates.

To date, no studies have been reported on the perspectives of leaders in emergency management on critical and evolving issues and challenges in emergency management systems in its quest to save lives, mitigate injuries and safeguard community integrity. These challenges suggest the relevance and importance of authentic transformational leadership. Hence, this study probes the unique perspectives of key informants in emergency management systems that emerge, using a grounded theory approach that has been deployed in health care settings. ${ }^{[32-37]}$ In particular, grounded theory formed the methodological foundation of the phenomenological study of emergency management systems. This study uses a theoretical triangulation approach, whereby several conceptual leadership and open systems models are merged to form the theoretical framework for this key informant study. ${ }^{[38,39]} \mathrm{A}$ systems perspective of emergency management is informed by the theory of open complex adaptive systems, whereby systems are organize themselves in response to external environmental stimuli in the form of small to catastrophic emergency events, all requiring systems intervention to safeguard lives and mitigate injuries. ${ }^{[40-47]}$ Emergency management systems are composed of five complex subsystems, each with unique and specific internal self-organizing processes. These are summarized in Table 1.

Table 1. Emergency management subsystems with key processes

\begin{tabular}{|c|c|c|c|c|}
\hline Emergency prevention & Emergency preparedness & Emergency medical care & $\begin{array}{l}\text { Emergency recovery and } \\
\text { rehabilitation }\end{array}$ & $\begin{array}{l}\text { Emergency review and } \\
\text { adaptive learning }\end{array}$ \\
\hline $\begin{array}{l}\text { Issues analysis } \\
\text { Primary prevention } \\
\text { Risk assessment } \\
\text { Scenario analysis } \\
\text { Secondary prevention } \\
\text { Stakeholder analysis } \\
\text { Strategic forecasting }\end{array}$ & $\begin{array}{l}\text { Business continuity plans } \\
\text { Contingency planning } \\
\text { Emergency plans } \\
\text { Emergency resources } \\
\text { Emergency training } \\
\text { Environmental scanning } \\
\text { Mitigation planning } \\
\text { Recovery plans } \\
\text { Response plans } \\
\text { Simulation exercises } \\
\text { Surge capacity planning } \\
\text { Threat analysis } \\
\text { Vulnerability analysis }\end{array}$ & $\begin{array}{l}\text { Care interventions } \\
\text { Community responses } \\
\text { Convergence management } \\
\text { Diagnosis and treatment } \\
\text { Evacuation } \\
\text { Incident command centers } \\
\text { Logistics } \\
\text { Information management } \\
\text { Military command centers } \\
\text { Primary hospital care } \\
\text { Resuscitation/stabilization } \\
\text { Search/rescue operations } \\
\text { Security controls } \\
\text { Social media networks } \\
\text { Tertiary hospital care } \\
\text { Transportation care } \\
\text { Triage } \\
\text { Volunteer management }\end{array}$ & $\begin{array}{l}\text { Community reconstruction } \\
\text { Facility care } \\
\text { Home care } \\
\text { Psychiatric care } \\
\text { Recovery operations } \\
\text { Rehabilitation care }\end{array}$ & $\begin{array}{l}\text { After-action reviews } \\
\text { Comprehensive audits } \\
\text { Hot washes } \\
\text { Simulations } \\
\text { Virtual education }\end{array}$ \\
\hline
\end{tabular}

In addition, the competing values framework, espoused by Quinn and Rohrbaugh, suggests the appropriateness of an open systems model of leadership, with its primary empha- sis on external engagement and flexibility in responses for emergency management systems. ${ }^{[23]}$ This is summarized in Table 2. This model also points to the relevance of human 
relations and authentic leadership emphasizing internal flexi- leadership styles are also relevant and central in emergency bility and cohesion as secondary importance. Both the trans- management systems, but on subsystem levels. actional (internal processes) and directive (rational goals)

Table 2. Competing values framework of leadership adapted to the emergency management systems context ${ }^{[23]}$

\begin{tabular}{lllll}
\hline Model/Model attributes & Human relationships & Open systems & Internal processes & Rational goals \\
\hline \multirow{2}{*}{ Leadership role } & Mentor & Innovator & Monitor & Producer \\
& Facilitator & Broker & Coordinator & Director \\
Means & Cohesion & Flexibility & Information management & Planning \\
& Morale & Preparedness & Communications & Goal setting \\
Ends & HR development & Growth & Stability & Efficiency \\
& & Resourcing & Productivity \\
Internal/External & Internal & External & Internal & External \\
Flexibility/Control & Flexible & Flexible & Control & Control \\
Emergency management systems & High & Highest & Lower & Medium \\
\hline
\end{tabular}

Another model of importance is the one espoused by Burke and Litwin on transformational leadership. ${ }^{[17]}$ This model stresses the importance of such leadership in organizational effectiveness and change. These models when merged with complex adaptive behaviour systems models form the theoretical framework that best reflects the authentic transformational leadership context of emergency management systems. As shown in Figure 1, authentic transformational leadership meditates between external environments (the context of emergency events), the system vision and mission, performance effectiveness and the self-organizing emergency subsystem responses.

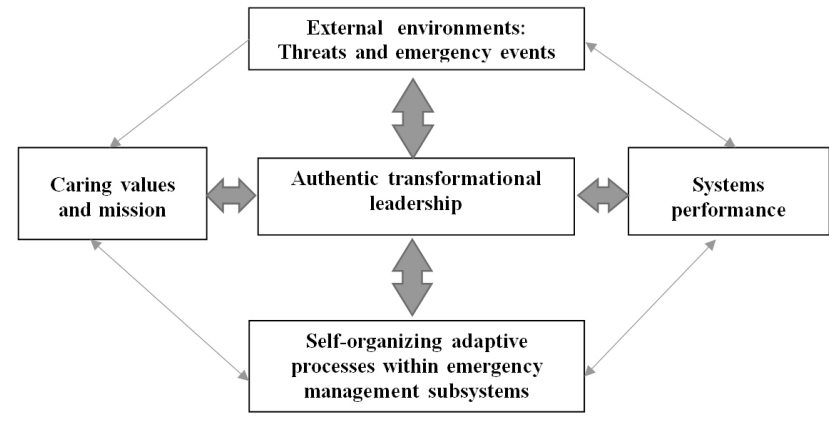

Figure 1. Authentic transformational leadership in the context of emergency management systems ${ }^{[17]}$

This adaptive systems model of authentic transformational leadership is posited to best approximate emergency management systems with its focus on adaptive, synergistic and creative problem-solving processes in highly complex, turbulent, dynamic and uncertain contextual environments. These environments suggest the need for authentic transformational leadership skill sets that emphasize flexibility, vision and foresight, innovation, high-order negotiation and persuasion skills to coalesce and forge diverse universe of stakeholders to work and perform synergistically within a range of organizational alliances and structures that transcend institutional confines. Emergency management systems are patientcentric systems that extend well beyond traditional hospital walls to incorporate where a wide range of professional care providers in synergistic actions focused on reducing mortality and morbidity rates in small-scale to large scale emergency events. Such systems require authentic transformational leaders who have regional care perspectives of a range of emergency events that bring together diverse care professionals for the benefit of patients and those encumbered by adverse external events. Furthermore in emergency management, authentic transformational leadership maintains caring and compassionate values that preserve and uphold personal health and well-being and communal integrity as crucial.

\section{Methodology}

This is qualitative study that explores the phenomenology of emergency management leadership, using a grounded theory approach. The study sought to elicit the individual perceptions and perspectives of emergency, government, health and technological professionals using a key informant methodology. The literature underscores the continuing relevance of such methodologies. ${ }^{[48-50]}$ Based on the extant literature, however, there have been no such studies reported on the perceptions of professionals on emergency management and leadership challenges in Canada nor internationally.

\subsection{Qualitative study design}

As in all qualitative studies of human subjects, the study objectives, protocol and research instrument were reviewed, then approved by an institutional research ethics board. Purposive sample size was determined by the six-week response 
time limit and the study objectives. In addition, chain referral sampling was used whereby professional bodies, such as the Canadian Association of Fire Chiefs, the Canadian Association of Social Workers, the Canadian College of Health Leaders and the Canadian Information Processing Society were points of entry that consented to issue a general invitation to their membership to participate. The key informant recruitment strategy was voluntary and confidential, as were the responses.

Within a six-week limit of the study, professional members were sent a link to a confidential online survey questionnaire in a secure database under the researcher's name with an online cloud-based company. The privacy and confidentiality standards were detailed and each respondent required to sign an explicit consent statement before proceeding with the questionnaire. Respondents had the option to elect to complete the exact questionnaire through a teleconference. There were 26 semi-structured and open-ended questions on perceived leadership attributes and skills, based on personal emergency experiences, systems performance management, future threats, emergency preparedness, technological developments and private sector partnerships.

A total of 103 key informants were sent invitations to participate and complete the research instrument online or, as in seven cases, through a teleconference with the researcher within the six week limit. Seventeen online questionnaires had negligible responses and were dropped from the study. The response rate was 83.5 percent with 86 key informants, representing 81 organizations across Canada, including 2 from the United States. These organizations included: 16 Federal Government agencies; 17 Provincial government and regional health authorities; 16 municipal government and first responder units; 14 private sector firms involved with health care; 13 hospital and health care facilities; and 5 national professional associations. Of the total respondents, 89 percent were senior professionals with 10 or more years of experience. Moreover there were 28 health professionals, 15 government officials, 14 fire and rescue officers, 11 care providers; 10 military officers; 4 social workers and 4 information system professionals - all with relevant emergency management experience. Seven key informants opted to answer the questions by teleconference, during which the interviewer made detailed notes of the responses. The interviewer verbally summarized the key points to the interviewee thus affording the opportunity to correct or clarify any points.

The results of all questionnaires were then culled, analyzed and summarized into major themes.Through the open-ended online questionnaire format, the key informants espoused, provided and elaborated on textual data descriptions of what they experienced and perceived as leadership challenges in emergency management systems in their professional contexts. This open-ended approach evoked responses that were meaningful and particularly salient to each key informant and produced an array of results that were rich, explanatory and unanticipated.

\subsection{Qualitative analysis}

Consonant with a grounded theory approach, qualitative data was collected with repeated ideas, concepts and elements as tagged codes and part of the substantive coding. Theoretical memoing started with the first concept identified and continued right through the comparative analytical process of the text data. These codes were grouped and integrated into concepts and constructs, which then became the basis for a new theoretical base. The theoretical base that emerged was that of authentic transformational leadership operating within an open-system context that was at once dynamic, adaptive and complex. The validity of this approach was underscored by the high degree to which evoked concepts fit with the text data and were relevant in that reflected real concerns and evoked of the key informants. The emerging concept of authentic transformational leadership was workable in that it showed how problems are resolved and was modifiable in that new data could lead to changes to the model. The results also suggested the importance of accountable and caring emergency leadership; adaptive organizational cultures, knowledge management, systems transformation and performance outcomes, defined in terms of mortality, morbidity and community integrity.

\subsection{Study limitations}

Other invited associations including the Canadian Association of Chiefs of Police, the Paramedic Chiefs of Canada and the Canadian Nurses Association, but did not respond within the given four-week limit. The perspectives of their membership would have been interesting. Nevertheless, the membership in the Canadian College of Health Leaders provided access to diverse public safety and care professionals across the spectrum of emergency management systems in Canada.

\section{RESULTS}

This qualitative study produced a wide and very rich range of perspectives of key informants on emergency experiences, system performance, threats, emergency preparedness, technological developments, private sector partnerships and leadership - all of which were duly tagged, coded and analyzed. Through the subsequent process of theoretical memoing, three interrelated significant constructs emerged. These are presented below with a small sample of the diverse perspec- 
tives expressed.

\subsection{Emergency preparedness and performance}

One provincial government official commented: "It [the local disaster] was beyond anyone's experience and came on unexpectedly and viciously. The organization of communication was a significant challenge. As always, politics came into play and some key leaders were not visible to those having to make decisions at the front line. It seemed the leaders were jockeying for more "air time" than concerned about effectiveness. Roles and responsibilities were not clear. We were flying by the seats of our pants. There was no one stepping up to the plate."

Table 3. Summary of key informant actual emergency experiences and perceptions of threats

\begin{tabular}{|c|c|c|c|}
\hline Threat Categories & Examples & Key Informant Emergency Experiences & $\begin{array}{l}\text { Key Informant } \\
\text { Perceived Threats (\%) }\end{array}$ \\
\hline Biological & $\begin{array}{l}\text { Biological agents and attacks } \\
\text { Cardiovascular emergencies } \\
\text { Epidemics and pandemics } \\
\text { Food and/or water contamination } \\
\text { Food and/or water shortages } \\
\text { Immunity to antibiotics } \\
\text { Infectious diseases } \\
\text { Pandemic } \\
\text { Psychiatric disorders } \\
\text { Sports injuries and falls } \\
\text { Suicidal ideation and behaviors }\end{array}$ & $\begin{array}{l}\text { - Cardiovascular emergencies. } \\
\text { - Suicidal crisis intervention. } \\
\text { - H1N1 epidemic. } \\
\text { - Public venue suicide. } \\
\text { - SARS outbreak. } \\
\text { - Sudden deaths on public venues. }\end{array}$ & $26 \%$ \\
\hline Meteorological & $\begin{array}{l}\text { Blizzards } \\
\text { Heat emergencies } \\
\text { Hurricanes } \\
\text { Ice storms } \\
\text { Tornados } \\
\text { Wind storms }\end{array}$ & $\begin{array}{l}\text { - Hurricane Katrina restoration. } \\
\text { - Tornados touchdown points in rural Ontario. }\end{array}$ & $15 \%$ \\
\hline Technological & $\begin{array}{l}\text { Airline accidents } \\
\text { Bleves, conflagrations and firestorms } \\
\text { Chemical and gas explosions } \\
\text { Electrical grid failures } \\
\text { Environmental accidents } \\
\text { Facility and plant fires } \\
\text { Hazards materials (HAZMAT) accidents } \\
\text { Home and farm accidents } \\
\text { Industrial and workplace accidents } \\
\text { Infrastructure collapse } \\
\text { Loss of energy, power and water resources } \\
\text { Marine accidents and disasters } \\
\text { Motor vehicle accidents (MVA) } \\
\text { Nuclear accidents } \\
\text { Oil and toxic spills } \\
\text { Pedestrian accidents } \\
\text { Rail accidents } \\
\text { Space accidents } \\
\text { Recreational/sports accidents } \\
\text { Structural accidents } \\
\text { Transportation accidents }\end{array}$ & $\begin{array}{l}\text { - Abandoned plant fire and toxic fumes plume } \\
\text { - Bicycle/MVA collision } \\
\text { - Bus accident with pediatric emergencies. } \\
\text { - Bus/semi-tractor trailer collision } \\
\text { - CBRNe team response to ammonia leak } \\
\text { - Chemical explosion and conflagration. } \\
\text { - Chemical recycling plant explosion and conflagration. } \\
\text { - Collapse of a safety rail at public event in Ontario. } \\
\text { - Commercial building fire. } \\
\text { - Ferry boat sinking in British Columbia. } \\
\text { - Hospital fires. } \\
\text { - Motorcycle collisions. } \\
\text { - Multi-automobile collisions. } \\
\text { - Oil refinery explosion and conflagration } \\
\text { - Pedestrian/automobile collision. } \\
\text { - Pediatric MVA } \\
\text { - Rail transport with hazardous chemicals/MVA collision. } \\
\text { - Recreational burn accident. } \\
\text { - Residential complex fire. } \\
\text { - Residential house fires. } \\
\text { - Rural All-Terrain Vehicle (ATV) accident. } \\
\text { - Small aircraft crash Ontario. } \\
\text { - Swiss Air } 111 \text { tragedy. } \\
\text { - Train/pediatric accident. } \\
\text { - Transport truck tumbles off a bridge into a dry river bed. }\end{array}$ & $29 \%$ \\
\hline Topological & $\begin{array}{l}\text { Droughts and water shortages } \\
\text { Earthquakes } \\
\text { Catastrophic floods } \\
\text { Forest and grassland fires } \\
\text { Landslides and sinkholes } \\
\text { Sinkholes } \\
\text { Space weather (solar flares) } \\
\text { Tsunamis }\end{array}$ & $\begin{array}{l}\text { - Catastrophic flooding in Manitoba. } \\
\text { - Earthquake disaster Haiti. } \\
\text { - Forest wildfires of British Columbia. } \\
\text { - Hurricane Katrina. } \\
\text { - Tornado in rural Ontario. }\end{array}$ & $12 \%$ \\
\hline
\end{tabular}


Table 3 summarizes five categories of threats on individuals and communities that constitute potentially significant emergencies; highlights the experiences of 46 respondents and identifies what they perceived as future threats. Forty-five per cent of respondents reported that updated business continuity, emergency preparedness and disaster recovery plans were in place in their organizations; 33 per cent had one or two of these in place; 21 per cent had none or did not respond. Performance management is predicated on emergency efficiency (response, transport and discharge rates) and effectiveness (mortality, morbidity, recovery, professional burnout and patient/family satisfaction rates). Key informants reported that the emergency care response system performed as well or better than expected, even if there was a $100 \%$ mortality rate, due to the catastrophic nature of the emergency event. Two key informants reported that despite excellent emergency response and care provided, professionals suffered from burnout and long-term post-traumatic stress disorder for which there was little recognition of nor support for. This underscored the importance of emergency professionals who themselves are potential victims in the course of their exercise of their duties and responsibilities.

\subsection{Technological developments and partnerships}

A senior provincial government official stated: "The greatest barrier is one of (sectorial) culture. In the private sector, poor performance is not tolerated. In the public sector, poor performance is. Very few were dismissed for poor performance during the SARS epidemic that cost Toronto approximately $\$ 1$ billion in lost revenue. If a business in the private sector lost $\$ 1$ billion, there would be significant accountability implications."

The key informants concurred that technological innovations and deployments are crucial in emergency management. From advanced transportation technologies, such as drones and driverless vehicles, to autonomic computers, massive terabyte storage capacities, nanotechnology, robotics and ubiquitous sensor technologies - all will have the potential to save lives and decrease injuries in the future. This optimism was tempered with the realization that the deployment of innovations is and will continue to be diffuse and inexorably slow in the light of sociopolitical and financial realities in Canada. The effectiveness of emergency management depends on reliable and secure telecommunications between critical systems that comply with interoperability standards. Key informants stressed that the lack of systems interoperability was one of the single greatest barriers to effective emergency systems. Moreover, they underscored that these barriers were sociopolitical in nature and not technological ones. Nor were key informants hopeful that partnerships with the private IT sector would bear fruit and be instrumental in the diffusion of key advanced technologies. Respondents stressed that differences in mission, perceptions and values between the sectors militated against cogent and stable partnerships. However, they did think that cooperation and engagement of the private sector as key stakeholders was deemed important in three critical areas, including: supply chain management networks, particularly in disaster recovery; joint emergency preparedness efforts; and technological innovations and diffusion.

\subsection{Emergency leadership and governance}

A senior provincial government official stated: "The governments at a national, provincial and municipal levels must work together to more clearly define roles and accountabilities toward planning response and recovery in disaster or emergency situations."

Table 4 highlights the key findings of the key informant study, which underscore authentic transformational leadership challenges in the future of emergency management. Key informants emphasized the central importance of leadership attributes, including: personality traits; political skills; social competencies; interpersonal influence; networking ability; personal integrity; perspicacity; and astuteness that promote trust and confidence confirming the extant literature. They also espoused that leaders should have a cogent knowledge and proven expertise in all emergency management phases, as well as a solid foundation of legal and sociopolitical contexts in which these phases take form. Cognitive skills, such as systems thinking in the face of complexity and pressing uncertainty, were also deemed important. Key informants repeatedly stressed the need for authentic transformational leadership in building collaborating networks of diverse professionals and community stakeholders through trust and respect relationships. Negotiation, conflict resolution and openness to innovation and change were also highlighted part of leadership skill sets. Highly-developed interpersonal and communication skills were deemed important, as were emotional intelligence and professional competence. Leadership competencies underscored analytical abilities and performance management. Key leadership attributes included accountability, discipline, empathy, professional ethics, personal integrity, and a high tolerance for stress and uncertainty. Repeatedly, the key informants underscored the importance of adaptability, courage, discipline, equanimity, initiative, and tenacity in the heat of battle. Situational and self awareness of personal limitations and the ability to delegate authority were deemed important. Key informants felt that authentic transformational leaders had duties and responsibilities to work closely with all levels of governance authorities to encourage cogent, proactive and visible approaches to 
emergency management. Some key informants believed that leaders had an important responsibility to militate and lobby for pertinent legislation and regulations that would facilitate systems interoperability and effective inter-organizational collaboration in emergency management.

Table 4. Salient highlights of key informant analysis using grounded theory of emergency management systems

\begin{tabular}{|c|c|}
\hline Key Informant & Varities \\
\hline Threats and vulnerability analysis & $\begin{array}{l}\text { - Compounding and escalation of threats and vulnerabilities } \\
\text { - Continuous monitoring and situational awareness of environmental dangers } \\
\text { - Perceptual understanding regional, national and international threats and vulnerabilities } \\
\text { - Risk mitigation strategies }\end{array}$ \\
\hline $\begin{array}{l}\text { Systemic integration of emergency management } \\
\text { systems }\end{array}$ & $\begin{array}{l}\text { - Attention to professional burnout and post-traumatic stress disorder } \\
\text { - Community and social recovery } \\
\text { - Ecology of emergencies } \\
\text { - Emergency command centers } \\
\text { - Emergency medicine } \\
\text { - Emergency preparedness engagement } \\
\text { - Interoperability of telecommunication systems } \\
\text { - Physical, mental and social rehabilitation processes } \\
\text { - Primary and secondary prevention strategies }\end{array}$ \\
\hline Collaborative network communities & $\begin{array}{l}\text { - Cogent and stable collaboration through mutual trust and sharability } \\
\text { - Community group support } \\
\text { - Critical role of military command } \\
\text { - Engagement of regional, national and international governance organizations } \\
\text { - Stakeholder identification and analysis }\end{array}$ \\
\hline $\begin{array}{l}\text { Equanimity, composure and control in the face of } \\
\text { horrors and tragic events }\end{array}$ & $\begin{array}{l}\text { - Ambiguity with great uncertainty in the face of fluid situations } \\
\text { - Courage and humility } \\
\text { - Decisiveness under conditions of informational and sensory overload and stress } \\
\text { - Objectivity while maintaining compassion } \\
\text { - Personal integrity } \\
\text { - Prior emergency and clinical experiences } \\
\text { - Understanding human and socio-political limitations }\end{array}$ \\
\hline Performance management & $\begin{array}{l}\text { - Ability to identify <mudas> (wastages) through gemba walks (walking through the frontlines) } \\
\text { - Adaptive learning } \\
\text { - Lean engineering applications to leverage efficiency } \\
\text { - Metrics to assess performance outcomes } \\
\text { - Metrics to monitor operational and response efficiencies } \\
\text { - Outcome-orientation that focuses on saving lives and reducing morbidities } \\
\text { - Performance analysis of emergency management components } \\
\text { - Promulgating a culture of continuous learning }\end{array}$ \\
\hline Coopting and engagement of private sector & $\begin{array}{l}\text { - Ability to bridge the different paradigms } \\
\text { - Collaboration in business continuity, emergency preparedness and recovery planning } \\
\text { - Innovation and implementation of information, communication and transportation technologies } \\
\text { - Private sector recognition and actualization of social responsibilities }\end{array}$ \\
\hline
\end{tabular}

\section{DISCUSSION}

This qualitative study based on grounded theory underscored the need for authentic transformational leadership for the future of emergency management systems. Integral to this leadership are a number of imperative skill sets that are specific to this domain, where life and death of so many are in the balance. These imperative skills include, but are not limited to: proactive precognition; threat analysis; collaborative network; systems engineering; strategic logistics; innovation implementation; and a caring vision. All this points to the need for emergency management leaders look beyond the institutions and adapt a systems and regional approach to the delivery of care.

\subsection{Proactive precognition}

A senior military officer in health care responded: "Create a sense of urgency. All parties must understand that it is crucial to recognize, prepare for, plan and understand what faces them."

Authentic transformational leaders must think of the "un- 
thinkable". Emergencies often incubate silently and mask dangerous warning signals, latent problems and potential failures. Denial of red flags of smoldering crises continues to be one of the greatest challenges in emergency management and that remain political and psychological by nature. On an individual level, the consequences of denial are shock, disbelief, paralysis, panic and even disregard. On an organizational level, failure to pay attention to warning signals leads to systemic paralysis, reactive responses, chaos and undue delays that often prove disastrous for individuals, organizations and communities. Emergencies challenge set beliefs, expectations, perceptions and understanding of reality. Emergencies are rarely only visual assaults. They also engage auditory, tactile and olfactory senses that shock and paralyze the psyche. They often challenge the normalized view of ordered entities of reality and convolute them into the unthinkable. Prior experiences with emergencies and high level training remain important as they are instrumental in overcoming the cognitive shock and information overload in actual emergencies. These cognitive skills allows authentic and transformational leaders to maintain equanimity and decisiveness in the exercise of their duties and responsibilities to save lives, reduce physical and psychological injuries and maintain organizational and communal integrity.

\subsection{Threat analysis}

A senior fire chief stated: "High level emergency public sector managers should take ownership of these [emergency] issues stressing the necessity for such programs. The public is generally complacent about emergency management and require a trusted individual to get the message out."

Authentic transformational leaders must analyze threats and vulnerabilities faced regionally, nationally and internationally. This points to the need for high-order environmental perception and situational awareness of the risks, threats, vulnerabilities and potentially needed resources. Mitigating risks include: strengthening the public health and safety legislation; judicious land use planning; closing socioeconomic gaps; health promotion; emergency preparedness; integrated medical care and recovery systems; community resilience and strengthening of critical emergency infrastructures nationally, provincial and regionally. None of these happen without cogent authentic transformational leadership in emergency management. Moreover, leaders understand that threats always have the potential to compound and to escalate posing further risks- all of which need to be prepared for.

\subsection{Collaborative networking}

A senior military health official posited: "The Canadian Forces own the $14^{\text {th }}$ health system that exists in Canada.
As we must maintain a pan-Canadian perspective in all we do, I have to define my community as the Canadian Forces geographically located across Canada and throughout the world. Communication of clear concise direction that can be interpreted and applied at a regional level, attention to regionally specific issues and respect and value of the input of multiple health care providers are critical to the success of our system."

Authentic transformational leaders must forge effective emergency collaborative networks between diverse stakeholders across a wide spectrum of professionals and communities. The survivability of individuals and viability of organizations and communities ultimately depend on them. Effective collaboration leads to information and resource sharing and systems interoperability that underpin effective emergency responses. The importance of identifying and engaging multiple stakeholders in emergency management through such networks remains paramount. Diverse stakeholders not only include the gamut of emergency professionals and care providers, but also advocacy and community groups, the military, non-governmental organizations and the private sector. Such collaborative engagements are crucial in building understanding, trust and resilience. Effective collaboration requires cogent inter-organizational linkages between multiple political and jurisdictional authorities, be they regional, national or international.

Authentic transformational leaders must engage individuals, organizations and communities in emergency preparedness as a social responsibility. This remains the vital core of planning and the praxis of the emergency management. Without effective business continuity, emergency response and recovery plans, individuals, organizations, and communities are far less able to effectively respond, cope and fully recover. Emergency preparedness is not just the domain of the trained emergency professionals, but central to all who are concerned with the lives of people and the integrity of organizations and communities. Resilience depends on engaging and creating social consciousness and motivation to help others. Emergency systems performance ultimately depends emergency preparedness and its integration as a social responsibility organizationally, regionally, nationally and internationally.

\subsection{Systems engineering}

A (recently retired) hospital administrator stated: "We need someone with the qualities of a General Eisenhower or General Patton to take command of implementing IT [Information Technology] collaboration. This leader will need legislative authority so that they can deal appropriately with naysayers and foot-draggers. The command and control structure of the military... Nothing short of that will work!" 
Authentic transformational leaders must strive to create high reliability organizations in emergency management through the deployment of a range of innovative technologies. Continuous learning and improvement and adaptability are the hallmarks of such organizations that mitigate the impact of, if not prevent, emergencies in environments efficiently and effectively. Creating and sustaining such organizations remains a challenge in the absence of effective and reliable telecommunications and advanced decision support systems. Systems interoperability is the basis for data and resource sharability between organizations. Inter-regional commonality in information technology standards, policies, processes and procedures strengthens the effectiveness of critical emergency management infrastructures. Germane to high-reliability organizations is the knowledge of and deployment of relevant systems engineering techniques, such as benchmarking, Kaizen (continuous improvement), lean methodologies, root cause analysis, simulations and total quality management in the pursuit of greater efficiency and positive outcomes in emergency management.

\subsection{Strategic logistics}

A hospital administrator maintained: "Emergency management is essentially a logistics problem and needs to be treated as such. We can learn a lot from airlines and aviation authorities. But none of this will solve the people issues, of course! That needs people working together regularly and getting to know one another, before all hell breaks loose."

Authentic transformational leaders must have logistical plans and strategies that assure effective access to supply chain networks, before they are needed. Deploying critical personnel, resources and supplies in place efficiently, harmoniously and effectively is of paramount importance, particularly in disaster and catastrophic situations. Forging strong linkages with military infrastructures with chains of command together with well-developed and secure transportation networks are key to effective delivery of emergency relief and resources. Moreover, leaders have to assure that logistical plans include access to effective supply chain networks through governance, military, non-governmental and private sector organizations.

\subsection{Innovation implementation}

An emergency medical social worker reflected: "Partnerships and integration of vision and processes between IT professionals and health care staff in emergency rooms, police, paramedics and home care services are the key ingredients to the successful delivery of medical care to patients. IT plays a key support role for linking these services together by assuring clear and effective communication by all parties

Published by Sciedu Press who are delivering the care to the patient."

Authentic transformational leaders must leverage innovative technologies to transform emergency management. The potential to transform emergency management through a panoply of technological innovations that are on the horizon is massive. Such technologies include advanced global communication and tracking systems, autonomic and intelligent systems, big-data storage systems, cloud-computing, driverless vehicles, drone technology, holographic applications, intelligent grid technologies, robotics, sensor nanotechnology, simulation learning systems, telemedicine, tele-surgery, and virtual incident command centers. Emergency leaders must pave the way through transformative changes in emergency management in collaboration with diverse stakeholders, including those from the private sector. Leaders must be technologically knowledgeable and able to effect positive deployments of innovations through systems and change management skills and strategies.

\subsection{Caring vision}

A senior emergency planner with a provincial government postulated: "Leading by example from the front means that a visible champion is required with sufficient authority and power to make things happen with and outside their particular sphere of influence. They must wield enough influence to challenge and convince others to follow suit. They must have vision and perseverance."

Authentic transformational leaders must have foresight and vision informed by deep compassion. Foresight and a compelling caring vision that inspires and motivates others are hallmarks of authentic transformational leaders. Leaders must have an intuitive understanding of the interrelatedness of environments and organizations. The ability to effectively communicate that vision and inspire others to collaborate and integrate emergency efforts is crucial. Deep empathy for others and compassion must inform that vision. Yet at the same time, leaders know and understand human and socio-political behaviour and limitations. Authentic transformational leaders have the humility to know that the forces at work may at times be beyond human comprehension and control. Leaders are neither omnipotent nor are they deities. Yet even with that, foresight and vision must still see the day and inspire others in the continuous struggle of not only saving lives, but also increasing the quality of lives.

\subsection{Implications for health care and hospital administra- tors}

A mental health social worker cited a case of suicidality: "An individual with intent to complete suicide was assessed and taken to the hospital. The hospital refused the patient. 
The system did not work. Trust and communication were lacking. Professional respect was not in existence. The hospital reacted to its perceived resource shortage and not to the needs of the patient. A community development approach that enlists the professional in the development of the process, rather than having the process presented to them at the time of an emergency. This will require more training and involvement than currently in place."

A (recently decedent) hospital administrator stated: "Disaster planning must be a key CEO responsibility, rather than an assignment for a junior staff member of an accreditation committee. Time!"

The universe of health care and hospital administrators is fraught with complex and competing health care priorities and challenges. As with emergency management leaders, hospital administrators must also look beyond the institutions and adapt a systems and regional approach to the delivery of care. Moreover, authentic transformational leadership with its emphasis on guiding transformational change, while maintaining strong caring values is paramount is relevant for hospital administrators too. It is interesting that almost 33 per cent of the respondents were in fact hospital and health care administrators with significant understanding and experience in emergency management. The importance of emergency preparedness, collaborating with regional health authorities and proactively recognizing the potential threats to communities underscore that hospitals must ever be at the ready. Whereas governance authorities judge the institutional performance, it is the public themselves who will judge hospital performance and their leaders come the time of the ultimate test of mass emergencies, disasters or catastrophes. They must not be found wanting.

\section{Conclusion}

Emergencies never end at the door of emergency departments, but rather when victims, care providers and communities have fully recovered from and emotionally accepted the ordeals experienced. The magnitude and frequency of regional, national and global emergencies, disasters and catastrophes will undoubtedly increase in the face of growing populations exposed to increasing threats in vulnerable environments. Authentic transformational leadership in emergency management will continue to have significant responsibilities in the future evolution of emergency critical infrastructures nationally and internationally. In the face of financial and resource constraints and given limited political will and public support, effective and sustainable emergency systems will continue to require strong and cogent authentic transformational leadership. In the quest to forge continuous collaboration and integration of emergency management systems, authentic transformational leadership will be crucial. Moreover, such leadership will be the catalyst that will create integrated virtual organizations through the deployment of advanced technologies that will interoperate regionally, nationally and internationally. Authentic transformational leadership that seeks to harmonize of emergency management policies and strategies with the regional, national and global governments and communities will actualize this future for the common good.

\section{ACKNOWLEDGEMENTS}

The author is deeply appreciative of the time and support of all the participants in this key informant study. He would also like to especially thank the Canadian College of Health Leaders, the Association of Fire Chiefs of Canada, the Association of Social Workers of Canada and the Canadian Information Processing Society for their kind cooperation and assistance.

\section{CONFlicts OF INTEREST Disclosure}

There are no competing interests in this paper.

\section{REFERENCES}

[1] Cheng SS. Crisis communication failure: A case study of typhoon Morakot. Asian Soc Sci. 2013; 9(3): 18-32. http://dx.doi.org $/ 10.5539 /$ ass.v9n3p18

[2] Eshghi K, Larson RC. Disasters: Lessons from the past 105 years. Disaster Prev Manage. 2008; 17(1): 62-82. http://dx.doi.org $/ 10.1108 / 09653560810855883$

[3] Henstra D. Evaluating local government emergency management programs: What framework should public managers adopt? Publ Admin. Rev. 2010; 70(2): 236-46. http://dx.doi.org/10.1111 $/ j .1540-6210.2010 .02130 . x$

[4] Ibrahim MS. An overview on the technological disasters. Disaster
Prev Manage. 2007; 16(3): 380-90. http://dx.doi.org/10.11 08/09653560710758332

[5] Ilhan AM. The humanitarian relief chain. SEast Eur J Econ Bus. 2011; 6(2): 45-54. http://dx.doi.org/10.2478/v10033-011 $-0015-\mathrm{x}$

[6] Kapucu N, Arslan T, Demiroz F. Collaborative emergency management and national emergency management network. Disaster Prev Manage. 2010; 19(4): 452-68. http://dx.doi.org/10.1108/0 9653561011070376

[7] Kumar S. Managing risks in a relief supply chain in the wake of an adverse event. OR Insight. 2011; 24(2): 131-57. http://dx.doi.o $\mathrm{rg} / 10.1057 /$ ori. 2011.4 
[8] McEntire D. Understanding and reducing vulnerability: From the approach of liabilities and capabilities. Disaster Prev Manage. 2011; 20(3): 294-313. http://dx.doi.org/10.1108/0965356111114 1736

[9] McGuire M, Silvia C. The effect of problem severity, managerial and organizational capacity, and agency structure on intergovernmental collaboration: Evidence from local emergency management. Publ Admin Rev. 2010; 70(2): 279-88. http://dx.doi.org/10.1111 /j.1540-6210.2010.02134.x

[10] Shughart WFII. Disaster relief as bad public policy. Indep Rev. 2011; 15(4): 519-39.

[11] Simpson NC, Hancock PG. Fifty years of operational research and emergency response. J Oper Res Soc. 2009; 60(05): S126-139. http://dx.doi.org/10.1057/jors.2009.3

[12] Van de Vactor JD. Cognizant healthcare logistics management: Ensuring resilience during crisis. IJDRBE. 2011; 2(3): 245-55. http://dx.doi.org/10.1108/17595901111167114

[13] Van De Walle B, Turoff M. Decision support for emergency situations. ISeB. 2008; 6(3): 295-316. http://dx.doi .org/10.1007 /s10257-008-0087-z

[14] Xu K, Li W. An ethical stakeholder approach to crisis communication: A case study of Foxconn's 2010 employee suicide crisis. J Bus Ethics. 2013; 117(2): 371-86. http://dx.doi.org/10.1007/s 10551-012-1522-0

[15] Aaron GA. Transformational and transactional leadership: Association with attitudes toward evidence-based practice. Psychiatr Serv. 2006; 57(8): 1162-1169. http://dx.doi.org/10.1176/ps. 20 06.57 .8 .1162

[16] Brown TM, Holland J, Bokowy KL, et al. Can transformational programs aimed at improving hospital management, leadership, and productivity systems affect financial performance? JHA. 2013; 2(4): 111-119. http://dx.doi.org/10.5430/jha.v2n4p111

[17] Burke WW, Litwin GH. A Causal Model of Organizational Performance and Change. J Manage. 1992; 18(3): 523-545. http: //dx.doi.org/10.1177/014920639201800306

[18] Caro DHJ. Towards systemic sustainable performance of TBI care systems: Emergency leadership frontiers. Int J Emerg Med. 2010; 3(4): 357-65. http://dx.doi.org/10.1007/s12245-010-025 2-2

[19] Coon CD, Bokowy KL, Horblyuk R, et al. The development and initial assessment of the strategy and leadership systems capability evaluation survey. Health Care Manage R. 2012; 31(4): 332-41. http://dx.doi.org/10.1097/hcm.0b013e31826fe2f9

[20] Goonan KJ, Stoltz PK. Leadership and management principles for outcomes-oriented organizations. Med Care. 2004; 42(4Suppl): III31-38. http://dx.doi.org/10.1097/01.mlr.0000120782 $.03031 . \mathrm{b} 4$

[21] Melo RCCP, Neves DS. Leadership and nurses' satisfaction with supervision. JHA. 2015; 4(4): 57-83. http: //dx. doi .org/10.54 $30 / \mathrm{jha} . \mathrm{v} 4 \mathrm{n} 4 \mathrm{p} 57$

[22] Phipps STA, Prieto LC. The influence of personality factors on transformational leadership: Exploring the moderating role of political skill. IJLS. 2011; 6(3): 430-447.

[23] Quinn R, Rohrbaugh J. A spatial model of effectiveness criteria: towards a competing values approach to organizational analysis. Manage Sci. 1983; 3(29): 363-377. http://dx.doi.org/10.1287/m nsc. $29 \cdot 3 \cdot 363$

[24] Wyld DC. Transformation leadership: When is it redundant? AMP. 2013; 27(2): 1-2.

[25] Avolio BJ, Gardner WL. Authentic leadership development: Getting to the root of positive forms of leadership. Leadership Quart. 2005;
16: 315-338. http://dx.doi.org/10.1016/j.leaqua.2005.0 3.001

[26] Bommer WH, Rubin RS, Baldwin TT. Setting the stage for effective leadership: Antecedents of transformational leadership behavior Leadership Quart. 2004; 15(2004): 195-210. http://dx.doi .org /10.1016/j.leaqua.2004.02.012

[27] Fairchild R, Ferng SF, Zwerner R. Authentic leadership practices informed by a rural hospital study. JHA. 2015; 4(2): 54-63. http: //dx.doi.org/10.5430/jha.v4n2p54

[28] Hayes PAJ, Omodei MM. Managing emergencies: Key competencies for incident management teams. Aust N Zeal J Organ Psych. 2011; 4(April 1): 1-10.

[29] Stock GN, McFadden KL, Gowen CR. Organizational culture, knowledge management, and patient safety in U.S. hospitals. Qual Manage J. 2010; 17(2): 7-26.

[30] Bass BM, Steidlmeier P. Ethics, character and authentic transformational leadership behaviour. Leadership Quart. 1999; 10(2): 181-217. http://dx .doi .org/10.1016/S1048-9843(99)00016-8

[31] Hearld LR, Alexander JA, Fraser I, et al. Review: how do hospital organizational structure and processes affect quality of care?: A critical review of research methods. Med Care Res Rev. 2008; 65(3): 259-299. http://dx.doi.org/10.1177/1077558707309613

[32] Beck TE, Plowman DA. Temporary, emergent interorganizational collaboration in unexpected circumstances: A study of the Columbia space shuttle response effort. Organ Sci. 2014; 25(4): 1234-1252. http://dx.doi.org/10.1287/orsc. 2013.0888

[33] Hede S. Lull after the storm? Municipal leaders reflect on multiple crisis experience. Disaster Prev Manage. 2011; 20(3): 281-293. http://dx.doi.org/10.1108/09653561111141727

[34] Nilakant V, Walker B, Van Heugten K, et al. Research note: Conceptualising adaptive resilience using grounded theory. New Zeal J Employment Relat (Online). 2014; 39(1): 79-86.

[35] Nilsson S, Sjöberg M, Larsson G. A civil contingencies agency management system for disaster aid: a theoretical model. Int J Organ Anal. 2010; 18(4): 412-429. http://dx.doi.org/10.1108/193 48831011081886

[36] Seidel S, Urquhart C. On emergence and forcing in information systems grounded theory studies: The case of Strauss and Corbin. J Info Tech. 2013; 28(3): 237-260. http://dx.doi.org/10.1057/jit .2013.17

[37] Sjöberg M, Wallenius C, Larsson G. Leadership in complex, stressful rescue operations. Disaster Prev Manage. 2011; 20(2): 199-212. http://dx .doi.org/10.1108/09653561111126120

[38] Halcomb EJ, Andrews S. Triangulation as a method of contemporary nursing research. Nurs Res. 2005; 13 (2): 71-82. PMid: 16416981. http://dx.doi.org/10.7748/nr2005.10.13.2.71.c5969

[39] Hussein A. The use of triangulation in social sciences research: Can qualitative and quantitative methods be combined? J Comp Soc Work 2009; 1: 1-12.

[40] Anyika EN. Challenges of implementing sustainable health care delivery in Nigeria under environmental uncertainty. JHA. 2014; 3(6): 113-126. http//dx.doi.org/10.5430/jha.v3n6p113

[41] deMattos PC, Miller DM, Park EH. Decision making in trauma centers from the standpoint of complex adaptive systems. Manage Decis. 2012; 50(9): 1549-1569. http://dx.doi.org/10.1108/00251 741211266688

[42] Deninson DR, Hooijberg R, Quinn R. Paradox and performance: Toward a theory of behavioural complexity in managerial leadership. Organ Sci. 1995; 6 (5): 524-540. http://dx.doi.org/10.1287 /orsc.6.5.524

[43] Junior VM, Pascucci L, Murphy JP. Implementing strategies in complex systems: Lessons from Brazilian hospitals. Braz Admin Rev. 
2012; 5(9): 19-37.http://dx.doi.org/10.1590/S1807-76922 012000500003

[44] Moerschell L, Lao TM. Igniting the leadership spark: An exploration of decision making and punctuated change. Emerg: Complexity Organ. 2012; 14(2): 54-68.

[45] Penprase B, Norris D. What nurse leaders should know about complex adaptive systems theory. Nurs Leadersh Forum. 2005; 9(3): 127-32. PMid: 16206697.

[46] Thomas CW, Corso L, Monroe JA. The value of the "system" in public health services and systems research. Am J Public Health. 2015; 105: S147-S149. PMid: 25689189. http://dx.doi.org/1 $0.2105 /$ AJPH. 2015.302625

[47] Zukowski RS. The impact of adaptive capacity on disaster response and recovery: Evidence supporting core community capabilities.
Prehosp Disaster Med. 2014; 29(4): 380-7. PMid: 24983418 http://dx.doi.org/10.1017/S1049023X14000624

[48] Di Ruggiero E, Cohen JE, Cole DC. The politics of agenda setting at the global level: Key informant interviews regarding the International Labour Organization decent work agenda. Global Health. 2014; 10(1): 56. http://dx . doi .org/10.1186/1744-8603-10-56

[49] Gamboa-Maldonado T, Marshak HH, Sinclair R, et al. Building capacity for community disaster preparedness: A call for collaboration between public environmental health and emergency preparedness and response programs. J Environ Health. 2012; 75(2): 24-9. PMid: 22984732.

[50] Morison S, Mcmullan C. Preparing for the future: Challenges and opportunities for management and leadership skills. Br Dent J. 2013; 214(1): E2. http://dx.doi.org/10.1038/sj . bdj.2012.1177 